\title{
Macrosomia-microphthalmia-cleft palate syndrome
}

INSERM

\section{Source}

INSERM. (1999). Orphanet: an online rare disease and orphan drug data base.

Macrosomia-microphthalmia-cleft palate syndrome. ORPHA:2432

Macrosomia-microphthalmia-cleft palate syndrome is a rare, genetic, multiple congenital anomalies/dysmorphic syndrome characterized by early macrosomia, bilateral severe microphthalmia and a protuberant abdomen with hepatomegaly. Additional reported features include brachycephaly, large fontanelles, prominent forehead, upturned nose and median cleft palate. Cyanotic apneic spells and overwhelming infection lead to death within the first 6 months of life. There have been no further descriptions in the literature since 1989. 